\title{
NADIR RASTLANAN BIR OLGU: TORAKOLITIAZIS
} A RARE CASE: THORACOLITHIASIS

\author{
Selçuk GÜRZ, Yasemin BiLGIN BÜYÜKKARABACAK, Volkan YILMAZ, Necmiye Gül TEMEL, Ahmet BAŞOĞLU \\ Ondokuz Mayıs Üniversitesi, Göğüs Cerrahisi Ana Bilim Dalı, Samsun
}

Cite this article as: Gürz S, Bilggin Büyükkarabacak Y, Yılmaz V, Temel NG, Başoğlu A. A Rare Case: Thoracolithiasis. Med J SDU 2019; 26(1): 104-106.

Öz

Torakolitiazis, plevral boşlukta bir veya daha fazla hareketli plevral taşın (kalsifikasyonlu veya kalsifikasyonsuz) herhangi bir travma, müdahale veya plörezi olmadan varlığıdır. Bu çalışmada, torakolitiazis tanısı alan olgu literatür bilgileri eşliğinde sunulmuştur.

Anahtar Kelimeler: Benign, kalsifikasyon, torakolitiazis

\section{Giriş}

Torakolitiazis, plevral boşlukta bir veya daha fazla hareketli plevral taşın (kalsifikasyonlu veya kalsifikasyonsuz) herhangi bir travma, müdahale veya plörezi olmadan varlığıdır. İnsidansı \% 0,1'den daha az bildirilen nadir görülen benign patolojilerdir (1). Bu çalışmada, Hemoptizi nedeniyle kliniğimize başvuran, periferik soliter nodül tanısı ile yapılan eksplorasyonda, perikard üzerinde mobil torakolitiazis tanısı konulan hasta literatür bilgileri eşiliğinde sunulmuştur.

\section{Olgu}

53 yaşında kadın hasta, tekrarlayan hemoptizi şikayeti ile kliniğimize başvurdu. Bilgisayarlı tomografide (BT); sol akciğer linguler segment komşuluğunda parame diastinal ve subplevral alanda yaklaşık $8 \times 10 \mathrm{~mm}$, kalsifikasyon içeren düzgün sınılı nodüler lezyon tespit edildi (Resim 1). Pozitron emisyon tomografide (PET) de; sol akciğer alt lob anterobazal segment komşulu-

\section{Abstract}

\section{Introduction}

Thoracolithiasis is present in the pleural space without anytrauma, intervention, or pleurisy, with one or more moving pleural stones (calcified or without calcification). In this study, we reviewed a patient has thoracolithiasis with knowladge of literature.

Keywords: benign, calsification,thoracolithiasis

ğunda parakardiyak yağlı doku içerisinde 16x9 mm, içerisinde mikrokalsifikasyonlar bulunan FDG negatif yumuşak doku görüldü. Bronkoskopi'de herhangi bir endobronşial oluşum ve kanama odağı tespit edilmedi. Video yardımlı torasik cerrahi (VATS) ile eksplorasyonda (Resim 2), sol hemitoraksta, parakardiyak yağlı doku içerisinde serbest, beyaz, $1 \times 2 \mathrm{~cm}$, solid nodül çıkarıldı (Resim 3). Histopatolojik inceleme; fibröz ve yer yer kalsifiye kapsül ile çevrili iç yüzünde yağ nekrozu ile uyumlu olabilecek alanlar içeren kalsifiye fibrotik nodül, torakolitiazis, olarak raporlandı. Hasta sorunsuz bir şekilde postoperatif 2. Günde taburcu edildi.

\section{Tartışma}

Torakolitiazis ilk kez 1968'de Dias ve arkadașları tarafından tanımlanmıştır (2). Plevral boşluk içinde hareket edebilen, çoğunlukla kalsifikasyon içeren, düzgün kenarlı, ovoid'plevra taşı' ve 'intratorasik taş' olarak da adlandırılan, benign nodüler bir patolojidir. Tek ya da birden fazla olabilirler $(2,3)$. Olgumuzda BT'de,

İletişim kurulacak yazar/Corresponding author: selcuk_gurz@hotmail.com Müracaat tarihi/Application Date: 04.06.2018 - Kabul tarihi/Accepted Date: 26.06.2018 (C) Copyright 2018 by Med J SDU - Available online at http://dergipark.gov.tr/sdutfd

@)Telif Hakkı 2018 SDÜ Tıp Fak Derg - Makaleye http://dergipark.gov.tr/sdutfd web sayfasından ulaşılabilir. 
hemitoraks inferiorunda, periferinde görülen torakolit eksplorasyonda, pozisyona bağlı olarak yer değiştirdiği ve parakardiak yağlı doku içinde yerleştiği tespit edilmiştir.

Çok nadir görülen bu benign patolojinin insidansı, Kinoshita ve arkadașlarının BT taraması alan 12.835 kişiden oluşan çalışmalarında $\% 0.086$ olarak bildirilmiştir. Aslında insidansın fazla olduğu, ancak asemptomatik olan bu patolojinin, çoğu kez belirlenemediği düşünülmektedir (1).

Her iki cinsiyette de eşit oranda görülürken, belli bir yaş dağılımı yoktur. Taşların yaklaşık\% 75 'i sol tarafIıdır(4).Diyafram yüzeyindeki plevral boşlukta, parankime komşu, göğüs duvarında, sol kalp boşluğuna bitişik olarak veya paraspinal boşluğun yakınında bulunurlar. Nadiren fissür içinde ya da intraparankimal olarak da yerleşebilirler. Olgumuzda literatür ile uyumlu olarak, sol plevral boşlukta parakardiyak yağlı doku içerisinde tek, düzgün kenarlı ovoid nodüler lezyon görülmüştür.

Etiyolojisi bilinmemekle birlikte yaygın teori; taşların perikardiyal yağın nekrozundan kaynaklandığıdır (5). Bu hem en sık görülen histolojiyle hem de taşların solda daha sık bulunduğu perikard komşuluğu ile örtüşür. Literatürde akciğer patolojisinin plevral taş geliştirme yatkınlığının olup olmadığı açık değildir. Laparaskopik cerrahiden sonra migrasyon yapan taşlar da torakolitiyazisi taklit edebilir. Bu taşları patolojik olarak teşhis etmek için cerrahi girişim gerekli olabilir. $(6,7)$.

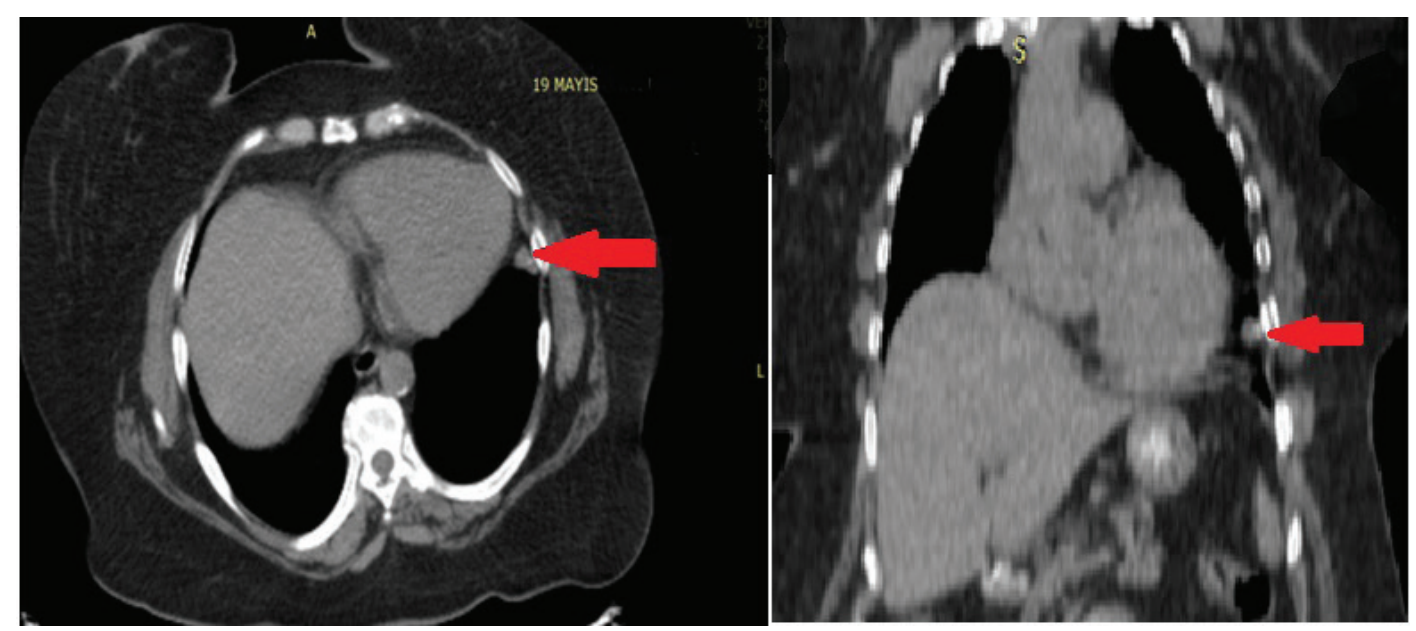

Resim 1: Tomografide, sol akciğer linguler segment komşuluğunda paramediastinal ve subplevral, $8 \times 10$ mm kalsifikasyon içeren düzgün sınırlı nodüler lezyon.

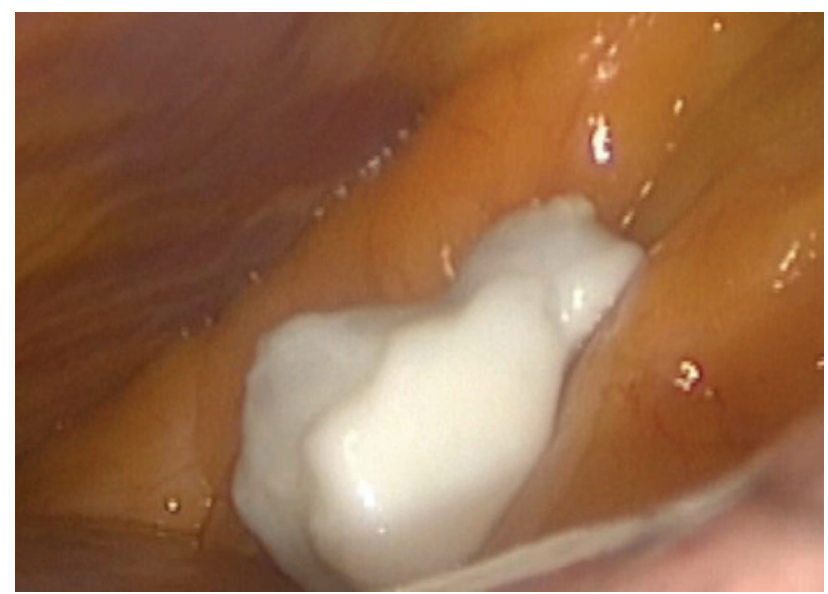

Resim 2: Sol hemitoraksta parakardiak yağlı doku içinde mobil kalsifik nodül.

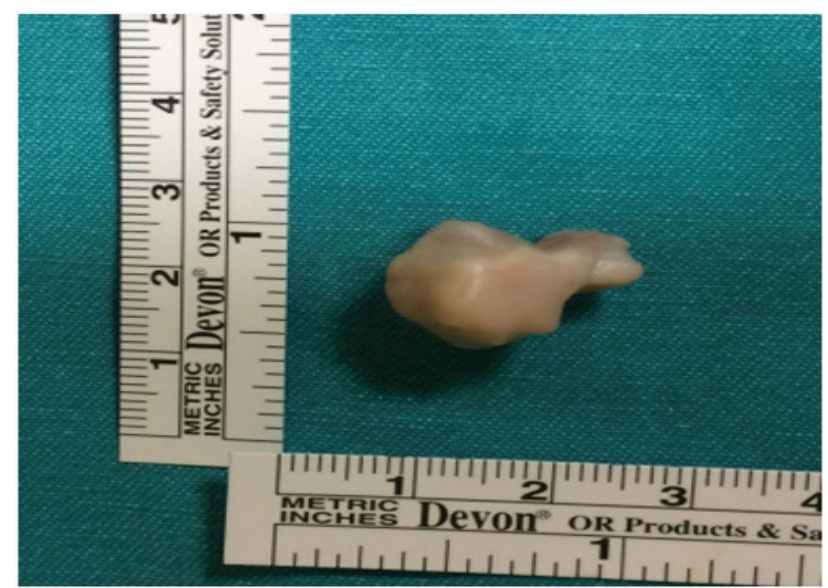

Resim 3: Torakoskopik olarak çıkarılan yaklaşık $1 \times 2 \mathrm{~cm}$ lik sert nodül. 
BT'de ovoid, düzgün kenarlı, total ya da parsiyel kalsifikasyon içeren boyutu 5-15 mm arasında değişen, nodüler lezyonlar olarak raporlanırlar. Kalsifikasyon noktasal, santral, periferik ya da diffüz, homojendir. Kalsifikasyon genel bulgu olmasına rağmen, bazen kalsifikasyon içermeyen yumuşak doku dansitesi șeklinde de görülebilirler. BT'de kalsifikasyon içermeyen boyutu büyüyen ve immobil lezyonlarda malignite olabileceği ayırıcı tanıda düşünülmeli ve tanısal tetkikler gerekirse genişletilmelidir (8).

Torakolitiazisi preoperatif dönemde teşhis etmek çok zordur. Genellikle başka bir nedenle yapılan eksplorasyonda, hastamızda olduğu gibi başka bir nedenle araştırııırken ya da otopsiler sırasında tespit edilir. Özellikle tümör hastalarında, BT'de görülen, spiküle ve kısmen kalsifikasyonlu nodüler metastazlar ile karıştırılabilmektedir. Bu durumda ayırıcı tanı için PET ve/veya eksplorasyon gerekebilir (3-8). Hastamızda da ilk çekilen tomografide kısmi merkezi bir kalsifikasyon tanımlanması sebebiyle PET planmış; FDG negatif olarak görülen nodül torakoskopik eksplorasyonla eksize edilmiştir.

Torakolitler; histolojik olarak, nekrotik plevral doku, lipom, pulmoner tüberküloz veya diğer granülomatöz süreçten bağımsız granülom veya makrofajların birleşiminden oluşurlar (6). Sıklıkla merkezi nekrozlu veya nekroz olmayan, yağlı çekirdekli dış fibröz tabakaya sahiptir. Hastamızda da histopatolojik incelemede, merkezde yağ nekrozu etrafında kalsifiye bir kapsül ile çevrili kalsifiye fibrotik nodül rapor edilmiştir.

Tek veya çoklu periferik kalsifiye ve özellikle mobil, intratorasik nodüllerin ayırıcı tanısında torakolitiyaz akılda bulundurulmalıdır. Tanısal ve terapötik amaçlı torakoskopik eksplorasyon, efektif ve güvenle uygulanabilecek minimal invaziv bir cerrahi tedavi seçeneğidir.

\section{Çıkar Çatışması}

Herhangibir çıkar çatışması yoktur.

\section{Kaynaklar}

1. Kinoshita F., Saida Y., Okajima Y., Honda S., Sato T., Hayashibe A. Thoracolithiasis: 11 cases with a calcified intrapleura loose body. J Thorac Imaging. 2010;25(1):64-67.

2. Dias A.R., Zerbini E.J., Curi N. Pleural stone. A case report. J Thorac Cardiovasc Surg. 1968;56(1):120-122.

3. Bakan S, Er ME, Memis ES, Kandemirli SG, Dikici AS, Kilic F, Akman C.Mobile Thoracolithiasis in a Patient With Lung Cancer:Ann Thorac Surg. 2015 Oct;100(4): 1472. doi: 10.1016/j. athoracsur.2015.06.094

4. Pineda V., Caceres J., Andreu J., Vilar J., Domingo M.L. Epipericardial fat necrosis: radiologic diagnosis and follow-up. AJR Am J Roentgenol. 2005;185(5):1234-1236.
5. Bolca C., Trahan S., Frechette E. Intrapleural thoracolithiasis: a rare intrathoracic pearl-like lesion. Thorac Cardiovasc Surg. 2011;59(7):445-446

6. Thitiporn S.,Chayanin N. Thin-section CT findings of thoracolithiasis, Japanese Journal of Radiology, 2017;35(7):355-356.

7. Iwasaki T.,Nakagawa K., Katsura H., Ohse N., Nagano T. Kawahara K. Surgically removed thoracolithiasis: report of two cases. Ann Thorac Cardiovasc Surg. 2006;12(4):279-282.

8. Gayer G. Thoracolithiasis-Computed Tomography Findings of Intrapleural Loose Bodies; Send to Semin Ultrasound CT MR. 2017 Dec;38(6):634-640. doi:10.1053/j.sult.2017.08.004. 